\title{
Genetic Variation of Wheat streak mosaic virus in the United States Pacific Northwest
}

\author{
Megan D. Robinson and Timothy D. Murray
}

Department of Plant Pathology, Washington State University, Box 646430, Pullman 99164-6430.

Current address of M. D. Robinson: 206-255 Russell Rd., Saskatoon, SK, S7K 7G8, Canada.

Accepted for publication 6 September 2012.

\begin{abstract}
Robinson, M. D., and Murray, T. D. 2013. Genetic variation of Wheat streak mosaic virus in the United States Pacific Northwest. Phytopathology 103:98-104.

Wheat streak mosaic virus (WSMV), the cause of wheat streak mosaic, is a widespread and damaging pathogen of wheat. WSMV is not a chronic problem of annual wheat in the United States Pacific Northwest but could negatively affect the establishment of perennial wheat, which is being developed as an alternative to annual wheat to prevent soil erosion. Fifty local isolates of WSMV were collected from 2008 to 2010 near Lewiston, ID, Pullman, WA, and the United States Department of Agriculture Central Ferry Research Station, near Pomeroy, WA to determine the amount of genetic variation present in the region. The coat protein gene from each isolate was sequenced and the data subjected to four

different methods of phylogenetic analyses. Two well-supported clades of WSMV were identified. Isolates in clade I share sequence similarity with isolates from Central Europe; this is the first report of isolates from Central Europe being reported in the United States. Isolates in clade II are similar to isolates originating from Australia, Argentina, and the American Pacific Northwest. Nine isolates showed evidence of recombination and the same two well-supported clades were observed when recombinant isolates were omitted from the analysis. More polymorphic sites, parsimony informative sites, and increased diversity were observed in clade II than clade I, suggesting more recent establishment of the virus in the latter. The observed diversity within both clades could make breeding for durable disease resistance in perennial wheat difficult if there is a differential response of WSMV resistance genes to isolates from different clades.
\end{abstract}

Wheat streak mosaic virus (WSMV) causes wheat streak mosaic, a potentially devastating disease of wheat (Triticum aestivum L.) with a worldwide distribution. WSMV is estimated to cause $5 \%$ yield loss every growing season and periodic epidemics with up to $100 \%$ loss in individual fields in the Great Plains region of the United States (9). WSMV was first observed in the United States in Kansas in 1919 and in breeding nurseries in Pullman, WA in 1954 (20,22). Typical symptoms of infection are stunting, a pale-green to yellow streaking in a mosaic pattern, fewer and smaller heads, and, with severe infection, shriveled seed and plant death. The virus is vectored by the wheat curl mite (Aceria tosichella Keifer), which is also the vector for other Potyvirus spp., including the virus responsible for High plains disease and Triticum mosaic virus $(30,31,35)$. WSMV is also transmitted by seed at relatively low rates, although this is not significant in most epidemics (14).

WSMV is a positive-sense, single-stranded, monopartite RNA virus in the family Potyviridae, genus Tritimovirus (type member: WSMV) (34). The virus genome is 9,384 nucleotides and lacks a poly-A tail (34). Four main clades of WSMV are currently recognized based on the nucleotide sequence of the coat protein gene (36). Clade A contains isolates from Mexico and clade B contains isolates from Central Europe and Russia. Clade B, also known as WSMV- $\Delta \mathrm{E}$, is characterized by a 3-nucleotide deletion at nucleotide position 8412 to 8414 , resulting in the deletion of $\mathrm{Gly}_{2761}$; members of this clade share 97.5 to $100 \%$ nucleotide sequence identity (10). Clade C contains isolates from Iran and clade D contains isolates from the United States, Canada, and Turkey

Corresponding author: T. D. Murray; E-mail: tim.murray@wsu.edu

http://dx.doi.org/10.1094/PHYTO-05-12-0108-R

(c) 2013 The American Phytopathological Society
$(6,33)$. Recent isolates collected from Turkey clustered in clade B, resulting in the hypothesis of two distinct genotypes coexisting in Turkey (10). Clade D was subdivided into four subclades: D1 contains isolates from the American Pacific Northwest (APNW); D2 contains isolates from Kansas and Colorado; D3 contains of isolates from Kansas, Kentucky, Ohio, and Missouri; and D4 contains isolates from Kansas and Nebraska, including Sidney 81 (36). The isolates in clade D are closely related, sharing $\geq 96.4 \%$ nucleotide identity (36). The APNW isolates have a pairwise nucleotide identity 98.3 to $99.1 \%$ and have not been discovered elsewhere in the United States (36).

In 2002, WSMV was reported in Australia and Argentina. Based on phylogenetic analysis of the nucleotide sequence of the coat protein gene, these isolates shared sequence similarity to those from the APNW $(6,33)$. It was hypothesized that the initial introduction in Australia resulted from seed infected with WSMV. Infected seed was transported to Australia through CIMMYT, grown in post-entry facilities in Tamworth, and spread throughout the country (6). This initial infection is thought to have occurred 10 to 20 years ago, and recent distribution of new wheat cultivars in combination with a slow build-up of inoculum and small, local outbreaks delayed detection of the virus (2). WSMV was first reported in Argentina in 2002 in the Cordoba province (33); its distribution in Argentina is not well known at this time.

Over one-third of the world's arable land has been lost to soil erosion (4). In the Palouse region of southeastern Washington, it is estimated that $\approx 10 \%$ of the cropland has lost all of its original topsoil and $60 \%$ of the remaining farmland has lost 25 to $75 \%$ of its topsoil since agriculture started in the region (29). Perennial wheat is being investigated as an alternative to annual wheat planted in areas with high potential for soil erosion (39). Aside from the prevention of soil erosion and degradation, perennial wheat has other advantages such as reduced labor costs, water and nutrient conservation, carbon sequestration, and increased soil 
microbial activity (29). Perennial wheat is projected to survive for 3 to 5 years and will be harvested alongside annual winter wheat.

WSMV and its vector are common in eastern Washington and north Idaho, surviving largely on wild grasses (11). However, environmental conditions are not favorable for the virus or vector and, consequently, wheat crops usually escape infection, such that epidemics are infrequent. Furthermore, WSMV may have a detrimental impact on the establishment of perennial wheat as a new crop because severe WSMV infection results in decreased yields and may reduce year-to-year survival. Perennial wheat could also serve as an important reservoir for the virus unless durable resistance is incorporated.

The objective of this study was to determine the extent of genetic diversity of WSMV in the APNW to understand the population structure and its relationship to isolates from around the world. Information on where current isolates of WSMV in the Pacific Northwest fit into global clades as well as the potential impact of local virus isolates on breeding for WSMV resistance in perennial wheat are needed to inform breeding programs and advance development of perennial wheat as a new crop.

\section{MATERIALS AND METHODS}

Sample collection. Samples of wheat were collected from the southeastern wheat-growing area of Washington State and northcentral Idaho during August 2009 and May to August 2010. Samples were collected from Whitman, Adams, Garfield, Franklin, Walla Walla, Asotin, and Columbia Counties in Washington and Nez Perce County, south of Lewiston, ID. The Central Ferry Research Station and Spillman Farm also were surveyed for presence of the virus because WSMV was previously collected in these locations. Tissue from wheat displaying WSM-like symptoms was used to mechanically inoculate greenhouse-grown susceptible 'Stephens' at the two- to three-leaf stage. Inoculum was prepared by shredding five to six symptomatic leaves into $\approx 2$ - to 3 -cm long pieces, placing them in a mortar, adding $5 \mathrm{ml}$ of $0.01 \mathrm{M}$ sodium phosphate buffer $(\mathrm{pH} 7.0)$ containing diatomaceous earth (Celite 503; Sigma-Aldrich, St. Louis) at $0.1 \mathrm{~g} / \mathrm{ml}$, and then grinding with a pestle (19). Test plants were inoculated by rubbing leaves with a cheesecloth pad saturated with the inoculum. Inoculated plants were placed in a growth chamber at $26^{\circ} \mathrm{C}$ (day) and $15^{\circ} \mathrm{C}$ (night) with a 12-h photoperiod for 2 to 3 weeks and then assessed for presence of symptoms. Indirect enzyme-linked immunosorbent assay (ELISA) was conducted as previously described (3) to confirm WSMV infection. Each isolate was reinoculated onto Stephens three times in an effort to develop single virus isolates for investigation of genetic variation. Leaves from ELISA-positive plants were stored at $-80^{\circ} \mathrm{C}$ for nucleic acid extraction.

Sequencing. WSMV RNA was extracted using a modified Dellaporta method as previously described (5). Infected tissue was ground in liquid nitrogen and $1 \mathrm{ml}$ of Dellaporta buffer was added. After mixing, $140 \mu \mathrm{l}$ of $10 \%$ sodium dodecyl sulfate was added to each sample and incubated for $30 \mathrm{~min}$ at $65^{\circ} \mathrm{C}$, and then $250 \mu \mathrm{l}$ of $8 \mathrm{M}$ KOAC was added. After gently mixing the contents by inverting the tubes, samples were chilled on ice for $5 \mathrm{~min}$ and then centrifuged at $16,000 \times g$ for $8 \mathrm{~min}$. Supernatant $(\approx 600 \mu \mathrm{l})$ was collected and transferred to a new tube containing $300 \mu \mathrm{l}$ of isopropanol. After mixing, each sample was left on ice for $10 \mathrm{~min}$ and then centrifuged at $16,000 \times g$ for $10 \mathrm{~min}$. The supernatant was discarded and the pellet washed with $750 \mu \mathrm{l}$ of $70 \%$ ethanol. Samples were then centrifuged at $16,000 \times g$ for $5 \mathrm{~min}$, the supernatant discarded, and the pellet centrifuged again for $15 \mathrm{~s}$. Any remaining ethanol was removed and the pellet was resuspended in $30 \mu \mathrm{l}$ of sterile water.

For first-strand synthesis, $5 \mu \mathrm{l}$ of RNA was added to $0.2-\mathrm{ml}$ tubes and incubated at $65^{\circ} \mathrm{C}$ for $2 \mathrm{~min}$ to eliminate secondary structure of the RNA. Tubes were chilled briefly; then, $15 \mu \mathrm{l}$ of the following reaction mixture was added: $4 \mu \mathrm{l}$ of $5 \times$ First Strand Buffer (Invitrogen, Carlsbad, CA), $4 \mu \mathrm{l}$ of $2.5 \mathrm{mM}$ dNTPs (Genscript USA Inc., Piscataway, NJ), $2 \mu$ of $0.1 \mathrm{M}$ dithiothreitol (Invitrogen), $0.25 \mu \mathrm{l}$ of SuperScript II Reverse Transcriptase (Invitrogen), $0.25 \mu \mathrm{l}$ of RNase Out (Invitrogen), $4.25 \mu \mathrm{l}$ of sterile water, and $0.25 \mu \mathrm{l}$ of RCF1 (5'-AGCTGGATCCTTTTTTTTTT TTT-T-3') (21). The reactions were incubated at $42^{\circ} \mathrm{C}$ for $60 \mathrm{~min}$ and the cDNA was stored at $-20^{\circ} \mathrm{C}$ until needed. Reverse-transcriptase polymerase chain reaction (PCR) was performed to amplify the coat protein region of the genome, which was subsequently sequenced directly. A master mix consisting of $18.875 \mu \mathrm{l}$ of water, $2.5 \mu \mathrm{l}$ of $10 \times$ ThermoPol Reaction Buffer (New England BioLabs, Ispwich, MA), $0.5 \mu \mathrm{l} 10 \mu \mathrm{M}$ dNTP, $0.125 \mu \mathrm{l}$ of Taq DNA polymerase (New England BioLabs), $0.5 \mu \mathrm{l}$ of $10 \mu \mathrm{M}$ forward and reverse primers specific to the coat protein (CP-F, 5'-CGATTTTTTTTTTTTTTTGCCGTCGCCCT-3'

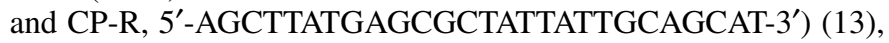
and $2 \mu \mathrm{l}$ of cDNA. PCR was performed in an iCycler Thermocycler (Bio-Rad, Hercules, CA). The PCR profile for all primer sets consisted of an initial denaturation at $95^{\circ} \mathrm{C}$ for $30 \mathrm{~s}$ followed by 35 cycles of $95^{\circ} \mathrm{C}$ for $1 \mathrm{~min}, 50^{\circ} \mathrm{C}$ for $1 \mathrm{~min}$, and $72^{\circ} \mathrm{C}$ for $2 \mathrm{~min}$. A final cycle of $72^{\circ} \mathrm{C}$ for $10 \mathrm{~min}$ and an infinite hold at $4^{\circ} \mathrm{C}$ completed the profile. PCR product was purified using the Qiagen PCR purification kit and sequenced by Elim Biopharmaceuticals, Inc. (Hayward, CA).

Phylogenetic analysis. Datamonkey (http://datamonkey.org) was used to examine recombination using the Genetic Algorithm Recombination Detector (GARD) to calculate the rate of nonsynonymous to synonymous mutations in the locally collected isolates before other analyses within Datamonkey were conducted. Selection pressure on the coat protein gene was investigated using single-likelihood ancestor counting (SLAC), fixed-effect likelihood (FEL), and random-effects likelihood (REL) analyses $(23,24)$. Recombination detection program 3 (RDP3) was used to investigate recombination events using RDP, GeneConv, Bootscan, MaxChi, Chimaera, SiScan, and 3Seq algorithms (18). Default settings were used for analysis and at least six of the methods used by the program required a $P$ value of $\leq 0.05$ for isolates to be characterized as recombinant isolates. The number of polymorphic sites, single variants, parsimony informative sites, invariant sites, haplotypes, and diversity $(\theta)$ were generated using DnaSP v5 (16).

Sequences were aligned using Clustal-X, and neighbor-joining and maximum parsimony phylogenies were estimated using MEGA under the default settings (37). Trees were constructed using all taxa with and without recombinant isolates. Additional WSMV coat protein sequences were retrieved from GenBank (http://www.ncbi.nlm.nih.gov). In all, 1,000 bootstrapped data sets were used to evaluate significance of tree topology. The model used for maximum-likelihood and Bayesian analysis was chosen using jModelTest $(12,25)$. For data sets with and without recombinant isolates, the model GTR $+\mathrm{I}+\mathrm{G}$ was chosen, using AIC to select the appropriate model. Phylip 3.69 was used to estimate a maximum-likelihood phylogeny with 500 bootstrapped data sets, which were used to assess support for nodes on the tree (8). Mr. Bayes was utilized for Bayesian analysis of the data; the GTR + I + G model was used and 2,000,000 generations were run (28). The consensus tree for maximum-likelihood and Bayesian analyses were visualized using FigTree v1.3.1.

\section{RESULTS}

Isolate collection. Fifty local isolates of WSMV were collected in 2008 to 2010 for sequence analysis (Table 1). Four isolates from 2008 were collected in the Pullman area and in long-term storage in the Murray lab. Samples consisting of several plants were collected from five different locations in 2009 from Spill- 
man Farm near Pullman, WA and 21 isolates, in all, were obtained. Samples consisting of multiple symptomatic leaves were collected from three commercial fields in southeastern Washington and north-central Idaho during 2010, resulting in 25 isolates. All positive samples were obtained from two areas: south of Lewiston, ID and the United States Department of Agriculture (USDA) Central Ferry Research Farm, located on the Snake River $\approx 96 \mathrm{~km}$ southwest of Pullman. Two isolates (2010-13-1 and 201013-2) collected near Bozeman, MT (provided by M. Burrows) were originally were isolates from the Great Plains Region of the United States.

Phylogenetic analysis. Phylogenetic analysis of APNW isolates and GenBank isolates (Table 2) was performed using the 1,049-bp sequence corresponding to nucleotide positions 8,180 to 9,224 of the Sidney 81 strain coat protein gene. Sequencing and alignment of local isolates revealed that some isolates shared a 3 -nucleotide deletion corresponding to 8,412 to 8,414 of Sidney

TABLE 1. Isolates of Wheat streak mosaic collected from eastern Washington and north-central Idaho from 2008 to 2010 and used for sequence analysis of the coat protein gene

\begin{tabular}{|c|c|}
\hline Isolate name & Location \\
\hline WSMV 2008-1 ${ }^{\mathrm{b}}$ & Field isolate, Pullman, WA \\
\hline WSMV 2008-2b & Field isolate, Pullman, WA \\
\hline WSMV 2008-3 $3^{\mathrm{b}}$ & Field isolate, Pullman, WA \\
\hline WSMV 2008-7 & Field isolate, Pullman, WA \\
\hline WSMV 2009-1-1 ${ }^{\text {b }}$ & Spillman Farm, Pullman, WA \\
\hline WSMV 2009-1-2 & Spillman Farm, Pullman, WA \\
\hline WSMV 2009-1-3 & Spillman Farm, Pullman, WA \\
\hline WSMV 2009-2-1 & Spillman Farm, Pullman, WA \\
\hline WSMV 2009-2-2b & Spillman Farm, Pullman, WA \\
\hline WSMV 2009-2-3 & Spillman Farm, Pullman, WA \\
\hline WSMV 2009-2-4 & Spillman Farm, Pullman, WA \\
\hline WSMV 2009-2-5 & Spillman Farm, Pullman, WA \\
\hline WSMV 2009-2-6 $6^{\mathrm{b}}$ & Spillman Farm, Pullman, WA \\
\hline WSMV 2009-3-1 & Spillman Farm, Pullman, WA \\
\hline WSMV 2009-3-2 $2^{b}$ & Spillman Farm, Pullman, WA \\
\hline WSMV 2009-3-3 & Spillman Farm, Pullman, WA \\
\hline WSMV 2009-3-4 & Spillman Farm, Pullman, WA \\
\hline WSMV 2009-3-5 & Spillman Farm, Pullman, WA \\
\hline WSMV 2009-4-1 ${ }^{\text {b }}$ & Spillman Farm, Pullman, WA \\
\hline WSMV 2009-4-2 & Spillman Farm, Pullman, WA \\
\hline WSMV 2009-4-3 $3^{b}$ & Spillman Farm, Pullman, WA \\
\hline WSMV 2009-4-4 & Spillman Farm, Pullman, WA \\
\hline WSMV 2009-4-5 & Spillman Farm, Pullman, WA \\
\hline WSMV 2009-5-1 ${ }^{b}$ & Spillman Farm, Pullman, WA \\
\hline WSMV 2009-5-2 & Spillman Farm, Pullman, WA \\
\hline WSMV 2010-1-1 ${ }^{b}$ & Central Ferry Research Station, WA \\
\hline WSMV 2010-1-2 & Central Ferry Research Station, WA \\
\hline WSMV 2010-2-1 ${ }^{\mathrm{b}}$ & Central Ferry Research Station, WA \\
\hline WSMV 2010-2-2b & Central Ferry Research Station, WA \\
\hline WSMV 2010-3-1 ${ }^{\mathrm{b}}$ & Central Ferry Research Station, WA \\
\hline WSMV 2010-4-1 ${ }^{b}$ & Central Ferry Research Station, WA \\
\hline WSMV 2010-4-2 $2^{b}$ & Central Ferry Research Station, WA \\
\hline WSMV 2010-5-1 ${ }^{\mathrm{b}}$ & Lewiston, ID \\
\hline WSMV 2010-5-2b & Lewiston, ID \\
\hline WSMV 2010-6-1 $1^{b}$ & Lewiston, ID \\
\hline WSMV 2010-6-2 $2^{b}$ & Lewiston, ID \\
\hline WSMV 2010-7-1 ${ }^{\mathrm{b}}$ & Lewiston, ID \\
\hline WSMV 2010-7-2b & Lewiston, ID \\
\hline WSMV 2010-8-1 ${ }^{\mathrm{b}}$ & Lewiston, ID \\
\hline WSMV 2010-8- $2^{\mathrm{b}}$ & Lewiston, ID \\
\hline WSMV 2010-8-3 $3^{b}$ & Lewiston, ID \\
\hline WSMV 2010-12-1 & Bozeman, Montana \\
\hline WSMV 2010-12-2 & Bozeman, Montana \\
\hline WSMV 2010-13-1 & Bozeman, Montana \\
\hline WSMV 2010-13-2 & Bozeman, Montana \\
\hline WSMV 2010-14-2 & Central Ferry Research Station, WA \\
\hline WSMV 2010-14-3 ${ }^{\mathrm{b}}$ & Central Ferry Research Station, WA \\
\hline
\end{tabular}

a Isolates are designated by the year of collection followed by field and plant number. Isolates with the same designation originated from the same source plant.

b Denotes isolates with a 3-nucleotide deletion from 8,412 to 8,414 of Sidney 81.
81. This deletion is characteristic of the Central European isolates, which corresponds to the deletion of $\mathrm{Gly}_{2761}$ (10).

Nine isolates showed evidence of recombination based on analysis with RDP3 (Table 3). Most of the recombination junctions occurred at the $3^{\prime}$ end of the sequence, with WSMV 2010-21and WSMV 2009-3-4B identified as the major and minor parent, respectively, for all recombinants. Because the history of each parental isolates creates a situation where a single tree cannot represent the history of the recombinant isolates (15), the phylogenetic analyses were conducted with and without the recombinant isolates to determine the effect of the recombination on phylogenetic placement of the taxa.

Neighbor-joining, maximum parsimony, maximum-likelihood, and Bayesian analyses revealed similar topologies with two major clades, designated clade I and clade II (Fig. 1). Clade I contained local isolates from 2008 to 2010 as well as those from Central Europe. Several subclades were supported within this clade; all 2008 isolates formed a subclade, another contained isolates 2010$10-1$ and 2010-10-2, and two subclades of 2009 isolates (2009-3-2, 2009-2-6, and 2009-2-3; and 2009-4-3, 2009-4-4, and 2009-4-1) that consistently clustered together. Clade II contained isolates from Australia, Argentina, and the United States, together with isolates from 2009 (1-1A, 1-1B, 1-3, 2-1, 2-5, 3-1, 3-3, 3-4A, 3-4B, 3-5, 4-2, and 4-5) and isolates 2010-9-2 and 2010-14-2. Isolates from Australia and Argentina and APNW isolates (including recent isolates from 2009 and 2010-14-2) formed a subclade, and isolates from the Great Plains and recent isolates from Montana (2010-12 and 2010-13) clustered together in another. Recombinant isolates (2009-1-1A, 2009-2-1, 2009-2-5, 2009-3-1, 2009-3-4A, 2009-4-2, 2009-4-5, and 2010-9-2) clustered with clade II with neighbor-joining, maximum parsimony, and maximum-likelihood analyses. Isolate 2009-2-4 did not cluster in either clade with neighbor-joining and maximum parsimony analyses; however, it clustered in clade II with maximum-likelihood analysis.

A different topology was observed from recombinant isolates when Bayesian analysis was applied. Isolates 2009-1-1A, 2009-2-4, 2009-2-5, 2009-3-4A, 2009-4-5, and 2010-9-2 clustered in clade I, and 2009-2-1, 2009-3-1, and 2009-4-2 clustered with clade II.

TABLE 2. Wheat streak mosaic virus (WSMV) isolates and Oat necrotic mottle virus (ONMV) obtained from GenBank and used in sequence analysis

\begin{tabular}{|c|c|c|c|}
\hline Isolate & $\begin{array}{l}\text { Accession } \\
\text { number }\end{array}$ & Geographic origin & Reference \\
\hline \multicolumn{4}{|l|}{ WSMV } \\
\hline ID96 & AF511618 & Idaho, United States & 33 \\
\hline ID99 & AF511619 & Idaho, United States & 33 \\
\hline WA94 & FJ348358 & Washington, United States & 33 \\
\hline WA99 & AF511643 & Washington, United States & 33 \\
\hline Mon96 & AF511630 & Montana, United States & 33 \\
\hline H98 & AF11615 & Kansas, United States & 33 \\
\hline Sidney 81 & AF057533 & Nebraska, United States & 34 \\
\hline Type & AF285169 & Kansas, United States & 1 \\
\hline TX96 & AF511641 & Texas, United States & 36 \\
\hline SD96 & AF511642 & South Dakota, United States & 36 \\
\hline Arg 1 & FJ348356 & Argentina & 33 \\
\hline Arg 2 & FJ348359 & Argentina & 33 \\
\hline Arg 3 & FJ348357 & Argentina & 33 \\
\hline Adelaide 1 & AY327868 & Australia & 6 \\
\hline Mt. Burdett & DQ888801 & Australia & 6 \\
\hline Galong & DQ888804 & Australia & 6 \\
\hline Horsham & AY327871 & Australia & 6 \\
\hline SP-5 & DQ462276 & Australia & 6 \\
\hline SP-6 & DQ462277 & Australia & 6 \\
\hline Czech & AF454454 & Central Europe & 26 \\
\hline Hungary & AF454456 & Central Europe & 26 \\
\hline Russia & AF454459 & Central Europe & 26 \\
\hline El Batan3 & AF285170 & Mexico & 1 \\
\hline ONMV & NC_005136 & United States & 32 \\
\hline
\end{tabular}


The major parent of recombinants isolates clustered in clade I and the minor parent was in clade II with all methods of analysis.

Similar tree topologies were observed when recombinant isolates were removed from the analysis (Fig. 2). Subclades observed in clade I were similar to when recombinants were included in the analyses, as well as an additional subclade (2010-4-2, 2010-11-1, and 2010-11-2). Clade II also had the same subclades when analyses were conducted with or without recombinant isolates. Resolution and support of interior branches increased for both clades when recombinant isolates were excluded from the analysis.

There was a difference in diversity, polymorphic sites, and number of haplotypes depending on the data included in the analysis (Table 4). When all data excluding outgroups were considered, $20.9 \%$ of the nucleotides were polymorphic and $14.1 \%$ were parsimony informative; the diversity statistic was 0.0462 . When clades I and II were considered separately $11.9 \%$ of the nucleotides were polymorphic in clade I, with $4.1 \%$ being parsimony informative, whereas $16.1 \%$ in clade II were polymorphic and $9.7 \%$ were parsimony informative. Clade II also had a higher diversity statistic when compared with clade II (0.0398 and 0.0202 , respectively). These results are similar to the results obtained from the phylogenetic analysis, where clade II had more interior branching that clade I with and without recombinant isolates in the analyses.

The subclade in clade II containing isolates from the APNW, Australia, and Argentina and locally collected isolates were analyzed separately. All isolates within this subclade were closely related; $6.2 \%$ of the sites were polymorphic, $2.6 \%$ were parsimony informative, and the diversity statistic was the lowest of all three groups at 0.0176 (Table 4).

Negative selection was the major form of selection pressure acting on these populations based on analysis with Datamonkey. GARD analysis revealed a recombining break point at site 351 in the alignment, in a region similar to that observed with RDP3 analysis. The ratio of nonsynonymous to synonymous substitutions (dN/dS) was 0.09 based on SLAC analysis and 0.08 based on FEL analysis, both signifying negative selection. Examining the individual codons where the majority of isolates were undergoing negative selection also supported this conclusion. Of 348 codons, 96 were undergoing selection and distributed throughout the alignment. Three were undergoing significant positive selection, one was supported by two methods of analysis, and two were supported by a single method. In total, 93 codons had significant negative selection; 42 of 93 were supported by only one method of analysis, 30 by two methods of analysis, and 24 by all three methods. FEL analysis detected the greatest number of negatively selected codons, including the majority of codons that were supported by only one method of analysis. Codons undergoing significant selection pressure, both positive and negative, were distributed throughout the sequence and not clustered in any region.

\section{DISCUSSION}

Two well-supported clades of WSMV are present in the APNW based on neighbor-joining, maximum parsimony, maximumlikelihood, and Bayesian analyses of the coat protein nucleotide sequence of the isolates collected in this study. Clade I shares sequence similarity to isolates from Central Europe and clade II contains isolates from Argentina, Australia, and previously collected isolates from the APNW (33). Isolates that share sequence identity with Central Europe have a three-amino-acid deletion that is characteristic of the Central European clade (WSMV- $\Delta \mathrm{E}$ ) and exhibit less genetic variation than clade $B$ isolates (10). This is the first report of WSMV- $\Delta \mathrm{E}$ isolates from Central Europe being discovered in the United States.

Negative selection was the primary selection pressure acting on the coat protein gene sequence as supported by $\mathrm{dN} / \mathrm{dS} \leq 1$ and codon-specific analysis supports results from previous studies $(1,6,36)$. Isolates from Australia and Argentina and those recently collected in the APNW were closely related, which is consistent with previous reports of a connection between isolates from the APNW and recent introductions discovered in Argentina and Australia (6,33).

Recombination was observed in nine isolates, eight of which were collected from Spillman Farm, Pullman, WA and near Lewiston, ID (2010-9-2) (Table 3). This suggests that the plants collected from Spillman Farm and the Lewiston area contained a mixed infection of WSMV isolates and that isolates from both clades, Central Europe, Russia, and the APNW, are present in both locations. The clustering pattern of the nine recombinant isolates prevents the formulation of a conclusion about their relationship to the other local isolates and from GenBank.

The diversity of isolates in this study has significant implications on breeding for WSMV resistance in both annual and perennial wheat because the different virus populations could differentially interact with virus resistance genes, making it difficult to develop durable resistance. Similarly, the large genetic variation observed in these populations could increase the potential for the evolution of resistance-breaking isolates (15). There is potential to transfer WSMV resistance genes from wild relatives of wheat such as Thinopyrum intermedium, which are resistant to WSMV in natural environments. Currently, several genes have been successfully transferred into wheat, including Wsm1, Wsm2, and $W s m 3$, although they are temperature sensitive and ineffective in temperatures $>24^{\circ} \mathrm{C}$ (17). However, Wsml is also effective against several Australian isolates and may prove to be useful in the APNW (7). Additional sources of resistance may be discovered and pyramiding multiple resistance genes could be an effective strategy to develop durable resistance to WSMV (7). Differential symptom expression and long-distance movement of WSMV isolates Sidney 81 and type strains on an inbred line of maize was controlled by a 4 -amino-acid differences in the $5^{\prime}$ region of the coat protein gene between the two isolates (38). This finding high-

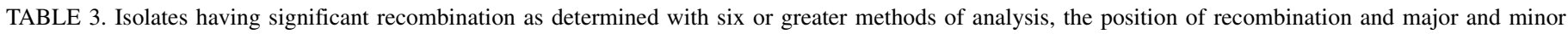
parent donors that contributed sequence identity to the recombinant isolates

\begin{tabular}{|c|c|c|c|}
\hline Isolate $^{a}$ & Position of recombination ${ }^{b}$ & Major parent & Minor parent \\
\hline WSMV 2009-1-1A & $477-1034$ & WSMV 2010-2-1 & WSMV 2009-3-4B \\
\hline WSMV 2009-2-1 & $477-1034$ & WSMV 2010-2-1 & WSMV 2009-3-4B \\
\hline WSMV 2009-2-4 & $469-1048$ & WSMV 2010-2-1 & WSMV 2009-3-4B \\
\hline WSMV 2009-2-5 & $422-1034$ & WSMV 2010-2-1 & WSMV 2009-3-4B \\
\hline WSMV 2009-3-1 & $359-1032$ & WSMV 2010-2-1 & WSMV 2009-3-4B \\
\hline WSMV 2009-3-4A & $477-1034$ & WSMV 2010-2-1 & WSMV 2009-3-4B \\
\hline WSMV 2009-4-2 & $359-1032$ & WSMV 2010-2-1 & WSMV 2009-3-4B \\
\hline WSMV 2009-4-5 & $477-1034$ & WSMV 2010-2-1 & WSMV 2009-3-4B \\
\hline WSMV 2010-9-2 & $485-1034$ & WSMV 2010-2-1 & WSMV 2009-3-4B \\
\hline
\end{tabular}

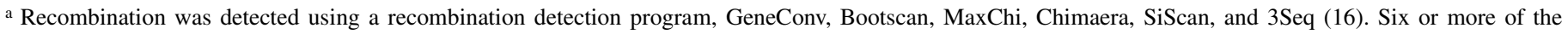
methods had to find significant recombination $(P \leq 0.05)$ for an isolate to be characterized as recombinant.

b Isolates are designated by the year of collection followed by field and plant number. Isolates with the same designation originated from the same source plant. 


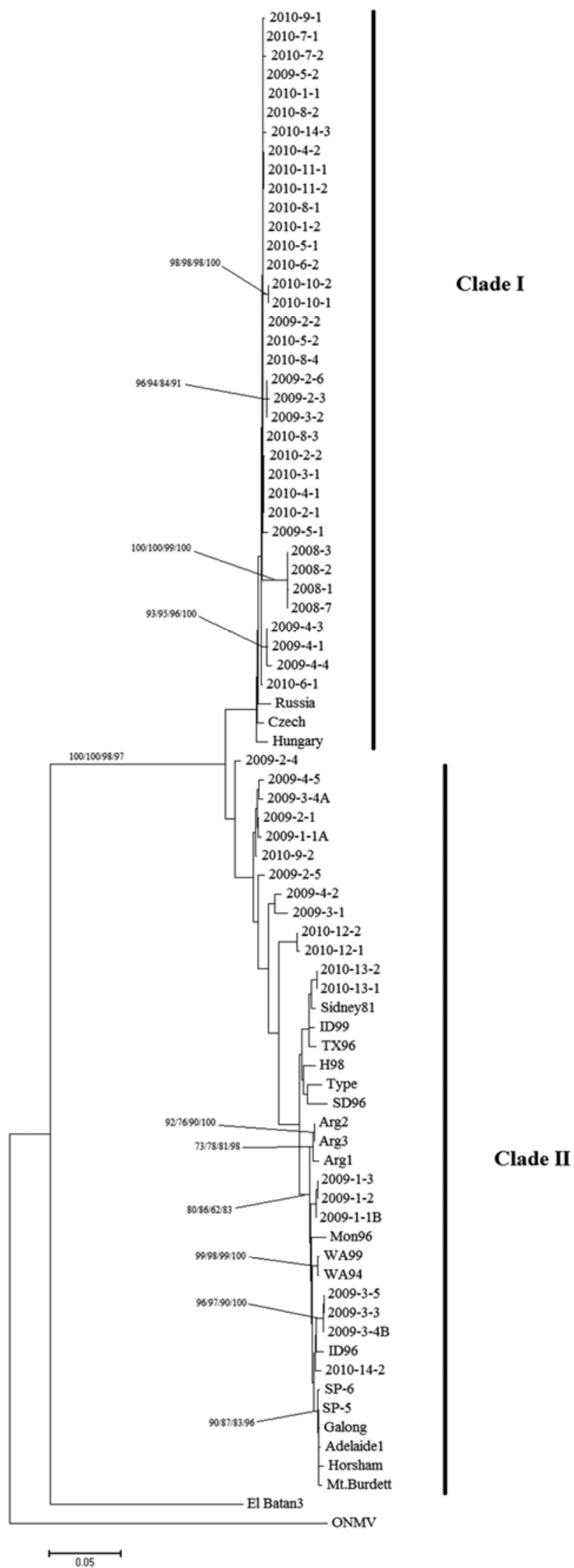

Fig. 1. Neighbor-joining phylogeny of the coat protein gene sequence of Wheat streak mosaic virus with bootstrapping support from neighbor-joining, maximum parsimony, and maximum-likelihood and posterior probability from Bayesian analysis, respectively, above significantly supported branches. Isolates El Batan3 and Oat necrotic mottle virus (ONMV) were used as outgroups for phylogenetic analyses (32). The scale represents 0.05 base substitutions per site.

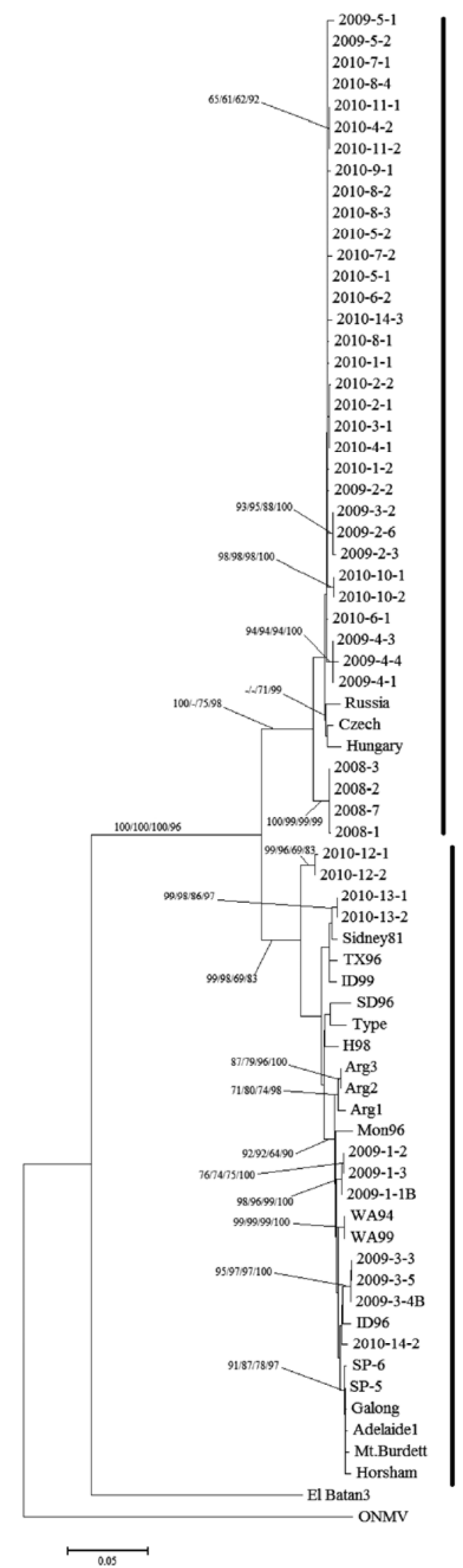

Clade I

Clade II

Fig. 2. Neighbor-joining phylogeny of the coat protein gene sequence of Wheat streak mosaic virus from analysis without recombinant isolates with bootstrapping support from neighbor-joining, maximum parsimony, and maximum-likelihood and posterior probability from Bayesian analysis, respectively, above significantly supported branches. Isolates El Batan3 and Oat necrotic mottle virus (ONMV) were used as outgroups for phylogenetic analyses (32). The scale represents 0.05 base substitutions per site. 
TABLE 4. Phylogenetically informative statistics for all data: clades I and II and the American Pacific Northwest (APNW) subclade

\begin{tabular}{|c|c|c|c|c|}
\hline Statistic $^{\mathrm{a}}$ & All data & Clade I & Clade II & APNW isolates $^{b}$ \\
\hline Number of polymorphic sites & 219 & 88 & 168 & 65 \\
\hline Single variants & 72 & 45 & 67 & 38 \\
\hline Parsimony informative & 147 & 43 & 101 & 27 \\
\hline Invariant & 822 & 954 & 873 & 979 \\
\hline Number of haplotypes & 61 & 26 & 35 & 17 \\
\hline Diversity $(\theta)^{\mathrm{c}}$ & 0.0462 & 0.0202 & 0.0398 & 0.0176 \\
\hline
\end{tabular}

a Phylogenetically informative statistics are those that are considered in the construction of phylogenetic trees.

b Included isolates that clustered in clade II within the subclade containing isolates from Argentina, Australia, and the APNW.

${ }^{c}$ Diversity statistic $\theta=$ per site nucleotide diversity.

lights the fact that small changes in the coat protein gene can have a large impact on virus biology. Sequence differences such as those observed between the two major clades within this study could potentially equate to differences in the behavior of WSMV isolates.

WSMV-infected plants were only found in two isolated areas despite the large survey area, and the isolates clustered into two different populations. Temperatures during summer 2010 were cooler than average, which could have affected virus and vector populations, therefore limiting disease development. Nevertheless, WSMV isolates collected in eastern Washington and northcentral Idaho are diverse and could make breeding for durable disease resistance difficult.

Genetic similarity to isolates from Australia and Argentina supports previous work that isolates discovered in recent outbreaks in these two countries are related to those sampled in the APNW $(6,33)$. However, the majority of isolates collected in this study clustered with isolates from Central Europe, which raises the question of whether these isolates were introduced from Central Europe to the APNW or if local isolates coevolved independently. The clustering of an isolate from Turkey into the same clade with isolates from the United States (26) revealed a situation that is potentially similar to that of the APNW, Australia, and Argentina. It was believed that the popularity of red winter wheat varieties originating from the Black Sea region resulted in substantial germplasm exchange during the past century, which could explain the relatedness between isolates from the two regions (26). These two cases may represent the first of many such incidents because WSMV is seedborne and the exchange of seed among breeding programs is a worldwide practice.

This is the first study to characterize the genetic diversity of WSMV isolates in the PNW. Based on the large amount of variation identified in a relatively small geographic area and the first report of European WSMV- $\Delta \mathrm{E}$ isolates in North America, further work is needed to characterize WSMV isolates from a wider geographic area within the PNW. Other tools are available that will make characterization of newly collected WSMV isolates faster than the methods used here. Gadiou et al. (10) developed two methods for specifically identifying European WSMV- $\Delta \mathrm{E}$ isolates based on restriction fragment length polymorphism analysis of the coat protein gene sequence and sequence-specific primers of the coat protein gene in one-step PCR that detect WSMV- $\Delta \mathrm{E}$ isolates. Neither of these methods was used in our study because it was a first survey and we elected to use sequence analysis of the coat protein gene to identify the total range of variation present. More recently, Rogers et al. (27) developed a method of fingerprinting WSMV isolates based on single nucleotide polymorphisms in the coat protein and helper component-protease genes that distinguishes WSMV from closely related viruses and is more rapid than sequence analysis. All of these methods should be useful in future studies of genetic variation of WSMV.

\section{ACKNOWLEDGMENTS}

Plant Pathology News Series Number 0593, Department of Plant Pathology, College of Human, Agricultural and Natural Resources Sciences
Agricultural Research Center, Project Number WNP00670, Washington State University, Pullman 99164-6430. Financial support of the USDANIFA and virus isolates from D. Seifers are gratefully acknowledged.

\section{LITERATURE CITED}

1. Choi, I.-R., Hall, J. S., Henry, M., Zhang, L., Hein, G. L., French, R., and Stenger, D. C. 2001. Contributions of genetic drift and negative selection on the evolution of three strains of wheat streak mosaic Tritimovirus. Arch. Virol. 146:619-628.

2. Coutts, B. A., Hammond, N. E. B., Kehoe, M. A., and Jones, R. A. C. 2008. Finding Wheat streak mosaic virus in south-west Australia. Aust. J. Agric. Res. 59:836-843.

3. Cox, C. M., Murray, T. D., and Jones, S. S. 2002. Perennial wheat germplasm lines resistant to eyespot, Cephalosporium stripe, and wheat streak mosaic. Plant Dis. 86:1043-1048.

4. Cox, T. S., Bender, M., Picone, C., Van Tassel, D. L., Holland, J. B., Brummer, E. C., Zoeller, B. E., Paterson, A. H., and Jackson, W. 2002. Breeding perennial grain crops. Crit. Rev. Plant Sci. 21:59-91.

5. Dellaporta, S. L., Wood, J., and Hicks, J. B. 1983. A plant DNA minipreparation: version II. Plant Mol. Biol. Rep. 1:19-21.

6. Dwyer, G. I., Gibbs, M. J., Gibbs, A. J., and Jones, R. A. C. 2007. Wheat streak mosaic virus in Australia: relationship to isolates from the Pacific Northwest of the USA and its dispersion via seed transmission. Plant Dis. 91:164-170.

7. Fahim, M., Mechanicos, A., Ayala-Navarrete, L., Haber, S., and Larkin, P. J. 2012. Resistance to Wheat streak mosaic virus - a survey of resources and development of molecular markers. Plant Pathol. 61:425-440.

8. Felsenstein, J. 1993. PHYLIP (Phylogenetic Inference Package), version 3.5c. Distributed by the author. Department of Genetics, University of Washington, Seattle.

9. French, R., and Stenger, D. C. 2003. Evolution of Wheat streak mosaic virus: Dynamics of population growth within plants may explain limited variation. Annu. Rev. Phytopathol. 41:199-214.

10. Gadiou, S., Kúdela, O., Ripl, J., Rabenstein, F., Kundu, J. K., and Glasa, M. 2009. An amino acid deletion in Wheat streak mosaic virus capsid protein distinguishes a homogenous group of European isolates and facilitates their specific detection. Plant Dis. 93:1209-1213.

11. Gillespie, R. L., Roberts, D. E., and Bentley, E. M. 1997. Population dynamics and dispersal of wheat curl mites (Acari: Eriophyidae) in north central Washington. J. Kans. Entom. Soc. 70:361-364.

12. Guindon, S., and Gascuel, O. 2003. A simple, fast and accurate algorithm to estimate large phylogenies by maximum likelihood. Syst. Biol. 52:696704.

13. Hall, J. S., French, R., Morris, T. J., and Stenger, D. C. 2001. Structure and temporal dynamics of populations within Wheat streak mosaic virus isolates. J. Virol. 75:10231-10243.

14. Jones, R. A. C., Coutts, B. A., Mackie, A. E., and Dwyer, G. I. 2005. Seed Transmission of Wheat streak mosaic virus shown unequivocally in wheat. Plant Dis. 89:1048-1050.

15. Lemey, P., Salemi, M., and Vandamme, A. 2009. The Phylogenetic Handbook: A Practical Approach to Phylogenetic Analysis and Hypothesis Testing, 2nd ed. Cambridge University Press, Cambridge.

16. Librado, P., and Rozas, J. 2009. DnaSP v5: a software for comprehensive analysis of DNA polymorphic data. Bioinformatics 25:1451-1452.

17. Liu, W., Seifers, D. L., Qi, L. L., Friebe, B., and Gill, B. S. 2011. A compensating wheat-Thinopyrum intermedium Robertsonian translocation conferring resistance to Wheat streak mosaic virus and Triticum mosaic virus. Crop Sci. 51:2382-2390.

18. Martin, D., Lerney, P., Lott, M., Moulton, V., Posada, D., and Lefeuvre, P. 2010. RDP3: A flexible and fast computer program for analyzing recombination. Bioinformatics 26:2462-2463.

19. Martin, T. J. 1978. Procedures for evaluating wheat streak mosaic virus resistance. Plant Dis. Rep. 62:1062-1066. 
20. McKinney, H. H. 1937. Mosaic diseases of wheat and related cereals. U. S. Dep. Agric. Circ. 442:1-23.

21. McNeil, J. E., French, R., Hein, G. L., Baenziger, P. S., and Eskridge, K. M. 1996. Characterization of genetic variability among natural populations of Wheat streak mosaic virus. Phytopathology 86:1222-1227.

22. Meiners, J. P., and McKinney, H. H. 1954. Wheat streak mosaic found in Washington. Plant Dis. Rep. 38:714-715.

23. Pond, S. L. K., and Frost, S. D. W. 2005. Not so different after all: A comparison of methods for detecting amino acid sites under selection. Mol. Biol. Evol. 22:1208-1222.

24. Pond, S. L. K., Posada, D., Gravenor, M. B., Woelk, C. H., and Frost, S. D. W. 2006. Automated phylogenetic detection of recombination using a genetic algorithm. Mol. Biol. Evol. 23:1891-1901.

25. Posada, D. 2008. jModelTest: Phylogenetic model averaging. Mol. Biol. Evol. 25:1253-1256.

26. Rabenstein, F., Seifers, D. L., Schubert, J., French, R., and Stenger, D. C. 2002. Phylogenetic relationships, strain diversity and biogeography of tritimoviruses. J. Gen. Virol. 83:895-906.

27. Rogers S. M., Payton, M., Allen, R. W., Melcher, U., Carver, J., and Flecther, J. 2012. Method: a single nucleotide polymorphism genotyping method for Wheat streak mosaic virus. Invest. Genet. Online publication. doi:10.1186/2041-2223-3-10

28. Ronquist, F., and Huelsenbeck, J. P. 2003. MRBAYES 3: Bayesian phylogenetic inference under mixed models. Bioinformatics 19:15721574.

29. Scheinost, P. L., Lammer, D. L., Cai, X., Murray, T. D., and Jones, S. S. 2001. Perennial wheat: the development of a sustainable cropping system for the Pacific Northwest, USA. Am. J. Alt. Agric. 16:146-150.

30. Seifers, D. L., Harvey, T. L., Martin, T. J., and Jensen, S. G. 1997. Identification of the Wheat curl mite as the vector of the High plains virus of corn and wheat. Plant Dis. 81:1161-1166.
31. Seifers, D. L., Martin, T. J., Harvey, T. L., Fellers, J. P., and Michaud, J. P. 2009. Identification of the Wheat curl mite as the vector of Triticum mosaic virus. Plant Dis. 93:25-29.

32. Stenger, D. C., and French, R. 2004. Complete nucleotide sequence of Oat necrotic mottle virus: A distinct Tritimovirus species (family Potyviridae) most closely related to Wheat streak mosaic virus. Archiv. Virol. 149:633-640.

33. Stenger, D. C., and French, R. 2009. Wheat streak mosaic virus genotypes introduced to Argentina are closely related to isolates from the American Pacific Northwest and Australia. Archiv. Virol. 154:331-336.

34. Stenger, D. C., Hall, J. S., Choi, I., and French, R. 1998. Phylogenetic relationships within the family Potyviridae: Wheat streak mosaic virus and Brome streak mosaic virus are not members of the genus Rymovirus. Phytopathology 88:782-787.

35. Stenger, D. C., Hein, G. L., Gildow, F. E., Horken, K. M., and French, R. 2005. Plant virus HC-Pro is a determinant of eriophyid mite transmission. J. Virol. 79:9054-9061.

36. Stenger, D. C., Seifers, D. L., and French, R. 2002. Patterns of polymorphism in Wheat streak mosaic virus: Sequence space explored by a clade of closely related viral genotypes rivals that between the most divergent strains. Virology 302:58-70.

37. Tamura, K., Dudley, J., Nei, M., and Kamur, S. 2007. MEGA4: Molecular evolutionary genetics analysis (MEGA) software version 4.0. Mol. Biol. Evol. 24:1596-1599.

38. Tatineni, S., Van Winkle, D. H., and French, R. 2011. The N-terminal region of Wheat streak mosaic virus coat protein is a host- and strainspecific long-distance transport factor. J. Virol. 85:1718-1731.

39. Xiwen, C., Lammer, D., Murray, T. D., and Jones, S. S. 2001. Perennial wheat development and genetic characterization of perennial growth habit. Pages 163-165 in: Proc. Int. Wheat Genet. Breed. Symp. Zhengzhou, China. 